\title{
Psychological and Physiological Changes in the Elderly Due to Agro-healing Activities
}

\author{
Hye Sook Jang ${ }^{1}$, Gyung Mee Gim², Sun-Jin Jeong ${ }^{1}$, Jae Soon Kim¹ ${ }^{1}$, and Eunha Yoo ${ }^{1 *}$ \\ ${ }^{1}$ National Institute of Horticultural \& Herbal Science, RDA, Wanju-gun 55365, Korea \\ ${ }^{2}$ R\&D Performance Evaluation \& Management Division, RDA, Deokjin-gu 54875, Korea
}

\section{ABSTRACT}

This study was conducted to investigate psychological and physiological changes of elderly affected by agro-healing activities. To meet the purpose, we conducted an agro-healing program with 20 elderly participants (average age 77.6 \pm 5.84 men and women) and once a week in total seven sessions. The Korean version of the Brief Encounter Psychosocial Instrument (BEPSI-K), Korean version of the Short Form of Geriatric Depression Scale (SGDS-K), participants' satisfaction with the program, Salivettes system method, and blood pressure were measured to find out the effects of agro-healing activities. BEPSI-K decreased by $5 \%$ in the high stress group although it was not statistically significant. The result of program satisfaction showed that $75 \%$ of the participants are satisfied with these activities. We investigated how many and what kind of chronic diseases the participants have had before they joined the program. As a result, hypertension was most common(35.6\%), followed by hyperlipidemia, diabetes, arthritis, lumbago, osteoporosis, and heart disease. Systolic blood pressure after the activities decreased significantly from $144.75 \mathrm{mmHg}$ (stage 1 hypertension), to $132.90 \mathrm{mmHg}$ (prehypertension stage). As a result of analyzing the correlations between general matters such as age, education level, average income of the participants, psychological scale and number of diseases, it was found that participants' satisfaction had a negative correlation with depression. In conclusion, agro-healing is very useful in relieving stress or lowering blood pressure for the elderly whose most common disease is hypertension. Agro-healing activities are proved to have positive uses in reducing the problems of the modern society with severe issues of the aging population.

Keywords: diabetes, hyperlipidemia, hypertension

\section{Introduction}

Senescence is the last stage of life and involves various problems due to the decline of physical, mental and social functions. Chronic diseases caused by physical aging faced in senescence not only psychologically intimidate the elderly but also slow down their response to negative emotions and external irritations, thereby bringing emotional changes such as anxiety and depression (Kim, 1998). In general, stress experienced by the elderly increases suicidal ideation when they cannot cope with various situations such as individual, environmental, psychological and social factors (Lee and Kim, 1999). Thus, mental health issues of the elderly today are very important (Kim, 1998). Increasing age is also related to obesity, decreasing physical activities and morbid state of metabolic syndrome (Jung et al., 2002; Kim, 2002). Reaction to stress is especially multidimensional and shows various forms depending on the individual, and even increases blood-sugar levels, pulses and blood pressure, weakens immunity, and causes diseases such as hypertension (Kim, 2005) Moreover, stress experienced frequently in daily life is an anxious and a threatening emotion felt when

This study was supported by the 2019 Horticultural and Herbal Science Program of the National Institute of Horticultural and Herbal Science of the Rural Development Administration (PJ01256402).

Received: September 23, 2019, Revised: October 2, 2019, Accepted: October 5, 2019

First author: Hye Sook Jang, jhs915@korea.kr, (1) https://orcid.org/0000-0003-3011-8694

*Corresponding author: Eunha Yoo, galaxy@korea.kr, (1) https://orcid.org/0000-0002-5794-2600 
humans face a situation that is difficult for them to handle psychologically and physically (Lazaru, 1993). When stress lasts long and becomes chronic, the sympathetic nerves become predominant and leads to hypersecretion of stress hormones, thereby decreasing immunity or causing many diseases that put people at risk (Kim et al., 2008).

Horticultural activities for the elderly are effective in increasing positive emotions such as interest, pleasure and expectancy (Lee, 1999). Plant gardening activities are also known to have significance in terms of rehabilitation and healing (Hewson, 1994). Plant activities with others not only reduce anxiety and stress but also increase interaction with neighbors, bringing energy and joy to the currently aging society and increasing satisfaction in life (Kim, 2013). Agro-healing activities that maximize interaction with plants must be able to support goals and provide understanding about the programs fit for the participants so that they can help heal the participants. Therefore, the objective of this study is to determine and present the utility of agro-healing programs for the elderly mostly exposed to chronic diseases in promoting physical and mental health of participants and bringing positive effects.

\section{Research Methods}

\section{Selection of subjects}

This study was conducted to determine the psychological and physiological changes of the elderly according to agro-healing activities. The subjects were the elderly going to the senior citizen center of an apartment located in Sejong, and their salivary cortisol (Salivettes system) and blood pressure were measured for physiological assessment. We explained the purpose of research, measurement items and methods to total 20 senior citizens, 3 male and 17

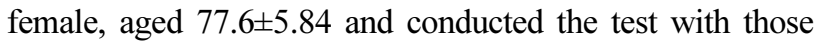
who have voluntary will to participate in the experiment and agreed to the consent. Food and beverages that may irritate the saliva such as coffee, green tea and caffeine are prohibited from 1 hour before the test.

\section{Tools for psychological assessment of participants}

The Korean version of the Brief Encounter Psychosocial Instrument (BEPSI-K) and the Korean version of the Short Form of Geriatric Depression Scale (SGDS-K) were used as the assessment tools for psychological characteristics, and program satisfaction was also examined.

\section{Brief Encounter Psychosocial Instrument-Korea (BEPSI-K)}

BEPSI-K was used for stress measurement. BEPSI-K is based on BEPSI developed by Frank and Zyzanski (1988) in six items to assess the negative effects of stress on health, redeveloped by Bae et al. (1992) and Yim et al. (1996) in Korea. Bae et al. (1992) adapted only five out of six BEPSI items, classifying the items into five levels to choose from. The revised version of BEPSI-K is used to rate the stress level in the past month on a 5-point Likert scale. By level, the BEPSI-K mean of 2.8 points or higher is classified as the high stress group, 1.8-2.6 points as the moderate stress group, and 1.6 points or lower as the low stress group (Kim et al., 1998; Shin et al., 2000). The reliability or internal consistency, Cronbach's $\alpha$, of BEPSI-K used in this study was .851 .

\section{Short Form Geriatric Depression Scale-Korea (SGDS-K)}

Depression was measured using the Short Form Geriatric Depression Scale (SGDS) developed by Yesavaga et al. (1983) and translated by Cho et al. (1999). SGDS is comprised of 15 items rated on a dichotomous scale of 'Yes' or 'No', and 10 items $(2,3,4,6,8,9,10,12,14,15)$ are scored as 1 point when given positive response, and five items $(1,5,7,11,13)$ are scored as 1 point when given negative response. Higher scores indicate more severe depression, and scores lower than 5 points are classified as normal, 5-9 points as suspected depression, and 10 points or higher as depression. In this study, Cronbach's $\alpha$ is .754.

\section{Tools for physiological assessment of participants}

Physiological assessment of participants was performed 
by collecting saliva and measuring blood pressure. Saliva was collected twice, pretest and posttest, in the first and last sessions of the agro-healing program. Cortisol secretion of adults is highest early in the morning and lowest between 8 p.m. and 2 a.m. the next morning (Posener et al., 2000). Thus, saliva collection was performed carefully so that the time difference pretest: 1 p.m.; posttest: 2 p.m.) is not big (Choi et al., 2014). In this study, saliva was collected with the Salivettes system using cotton. Saliva is likely to get contaminated when collecting salivary cortisol due to contact of hand or air, and thus the cautions in saliva collection are strictly obeyed to minimize contamination and precisely collect saliva. Saliva collection using the Salivettes system was based on Schwartz et al. (1998), and salivary cortisol analysis is conducted using ER HS SALIVARY CORTISOL kit (Salimetrics Inc. USA) reagent and VERSA Max Microplate Reader (Molecular device, USA) with the unit of analysis as $\mu \mathrm{g} / \mathrm{dL}$ (Jang et al., 2019). Increase in salivary cortisol indicates increase in stress reaction, and vice versa.

However, even though the collection method was precisely followed in saliva collection, not enough samples were collected from eight out of 20 participants, and thus saliva of only 12 participants were analyzed. A person's average amount of saliva flow rate per day is $1.0 \mathrm{~L}-1.5 \mathrm{~L}$, and saliva flow rate per minute is $1 \mathrm{ml} / \mathrm{min}$ (Saliva, n.d.). Thus, there were many cases of insufficient samples even though saliva was collected for 5 minutes in this study. Except for one participant, all others had hypertension, osteoporosis, diabetes or other illnesses. Those with general diseases such as hypertension, osteoporosis, gastrointestinal disturbance, diabetes, and cardiovascular disorders and those who take medication or are old tend to show decreased saliva flow rates and mouth dryness (Jang et al., 2006; Oh et al., 2019; Petersen and Yamamoto, 2005; Yang et al., 2008), which is found in about $30 \%$ of the elderly aged 60 and older (Jeong et al., 2006). The average age of the elderly participating in the agro-healing program of this study is $77.6 \pm 5.84$, and thus saliva collection was not carried out smoothly. Therefore, it is necessary to find or supplement simple methods of physiological assessment for the elderly through the results of this study.

\section{Laboratory settings and activities in Sessions 1-7 of the agro-healing program}

The agro-healing program was carried out once a week in total seven sessions (Table 1) from 1 p.m. to 3 p.m. at the outdoor garden in front of the apartment's senior citizen center and indoor space (Fig. 1). The room with light gray walls was $12.0 \mathrm{~m}$ long, $7.0 \mathrm{~m}$ wide and $2.6 \mathrm{~m}$ high, and the illumination of the table height from the floor was $600 \pm 10 \operatorname{lux}(\mathrm{UT} 383$ Mini Light Meters, Japan) on average and the temperature was $25 \pm 0.5^{\circ} \mathrm{C}$.

The agro-healing program was carried out once a week in total seven sessions with a professional instructor and assistant instructors, comprised of one main instructor (Urban Agriculture Manager, 2nd Grade Social Worker), one main assistant instructor (Urban Agriculture Manager, Healing Horticulture Instructor, 2nd Grade Field Trip Instructor), and two assistant instructors specialized in horticulture. The agro-healing activities were comprised of

Table 1. Agro-healing activities applied to the elderly

\begin{tabular}{cl}
\hline Session & \multicolumn{1}{c}{ Agro-healing activity } \\
\hline 1 & The first meeting; making my name tag, planting seedling in pots, seeding, and garden activity \\
2 & Understanding one's personality, transplanting seedling to a plastic cup, removing weeds in the garden \\
3 & Gathering flowers for pressed flowers, choosing flowers to match oneself and taking a picture with them, placing the collected \\
& flowers in newspapers and letting them dry \\
4 & Making a flower-basket for family and harvesting lettuce \\
6 & Making natural pest control solutions (using egg yolk oil and eggshell), making a scarecrow from recycled clothing \\
7 & Coloring nails with garden balsam, decorating a succulent plant pot and cutting \\
& garden plants
\end{tabular}




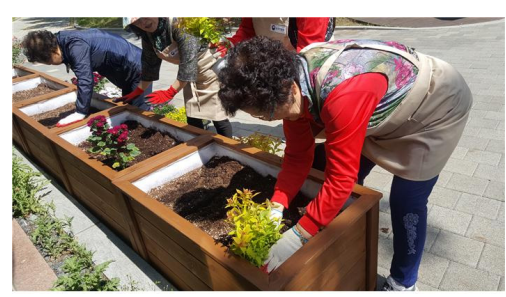

A

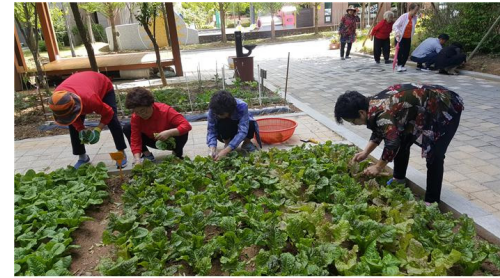

B



C

Fig. 1. Plant gardening activities in agro-healing program: (A) container gardening; (B) planting outside Silver Hall; (C) making pressed flower cards.

seeding, planting vegetable and flowering plant seedlings, making natural plant tonic and pest control agent, and sharing plants with neighbors using the plant box garden and garden in front of the senior citizen center.

Session 1 provided information on the direction of the entire program as well as the materials used. The participants made their name tags, which they had not been called much so far, and could reflect on themselves. They also introduced the seedlings and materials for seeding to planters and gardens, after which they mixed soil, seeded and planted the seedlings outdoors. The types of seedlings planted were Impatiens balsamina, Chrysanthemum morifolium, Spiraea japonica, Dimorphotheca, Callistephus chinensis, Bacopa mercardonia, Rosmarinus officinalis, Salvia greggii, Lactuca sativa, Capsicum annuum, and Solanum melongena seedlings, and Beta vulgaris seeded. They planted Impatiens balsamina seedlings to color their nails in garden balsam (Impatiens balsamina) with their neighbors in Session 6 and promote communication and volunteer sharing with neighbors. In Session 2, the participants tried to understand their personalities as plants also have personalities, planted seedlings into single pots to communicate and share plants with neighbors, and removed weeds so that vegetables in the garden can grow well. In Session 3, the participants could reflect on the meaning that they can turn negative outcomes into positive outcomes through traditional fairy tale "Farting Daughter-in-Law" with a professional instructor. They also collected pressed flower materials to use in Session 7 outdoors. Here, they looked back on the life they had as parents as well as their roles. And as they searched for natural objects that look like themselves to send to family or friends, they took pictures together and printed them out on an instant printer and spent some time to look back on the passing of time as they saw themselves in the pictures. They put the materials for plants to decorate pressed flower cards in newspapers so that they can dry naturally. In Session 4, they decorated flowers to give to their daughters-in-law or children to communicate with family by expressing their emotions in celebration of the Family Month of May with a professional florist. They also weeded out the vegetables in the garden and harvested and shared the lettuce that has grown.

In Session 5, they learned about insects and natural enemies of gardens and made egg yolk oil that is an eco-friendly pesticide and eggshell calcium that serves as tonic, studying the meaning of fertilizers and disease and insect pest control. Outdoors, they used the natural pesticide they made on the plants in the planter to easily prevent and control disease and insect pests. They also made a scarecrow to protect the garden using recyclable products like old clothes and hats, thinking of the high, blue autumn sky. In Session 6, children from the kindergarten in the apartment and residents are invited, and the elderly participants colored the visitors' fingers with garden balsam and spent time to interact with the neighbors. They also shared the pots where plants are planted to the neighbors to improve sociality of the elderly, which is anticipated to result in one pot of plants raised by each family. In Session 7, the participants made pressed flower cards with the materials they prepared in Session 3 and write letters to their family and friends. They also harvested lettuce and herbs they had grown in the garden and made mojitos and salads, sharing them with others as they talked about how sad they are to reach the final session, and how much fun they had throughout the activities. 


\section{Statistical analysis}

IBM SPSS ver. 25.0 is used for statistical analysis of this study. Cronbach's $\alpha$ is calculated for reliability analysis of the measurement tools. The Wilcoxon paired signed ranks test is conducted on salivary cortisol, Korean version of the Brief Encounter Psychosocial Instrument (BEPSI-K), and Korean version of the Short Form of Geriatric Depression Scale (SGDS-K); Pearson's on the correlation among the psychological scale, satisfaction and demographic characteristics; multiple response analysis on the number of diseases possessed by individual; and frequency analysis on program satisfaction and demographic characteristics.

\section{Results and Discussion}

\section{Demographic characteristics}

Of the 20 subjects, $65.0 \%$ were in their $70 \mathrm{~s}$ and $35.0 \%$ in their 80 s. $47.4 \%$ of them were middle school graduates, followed by $26.2 \%$ high school graduates, $21.1 \%$ elementary school graduates, and $5.3 \%$ college graduates or higher. Most of their average monthly income was less than KRW 400 thousand a month (35\%), followed by KRW 400 thousand to less than KRW 800 thousand a month (25.0\%), KRW 800 thousand to less than KRW 1.2 million a month (20.0\%) and KRW 1.2 million to less than KRW 1.6 million a month $(20.0 \%)$. As a result of examining the average number of visits to the pharmacy per month by individual, it was found that $63.2 \%$ visited the pharmacy once, followed by $21.0 \%$ visiting at least three times and $15.8 \%$ visiting twice. Except for one participant, 19 out of 20 participants were visiting the pharmacy at least once a month on average (data not shown).

\section{Stress scale and ratio of participants}

As a result of analyzing the stress scale and ratio of participants before and after participating in the agro-healing program, it was found that BEPSI-K was not statistically significant after participation compared to before, and their mean scores before and after the program were at least 4 points, putting them in the high stress group.
However, the results showed that BEPSI-K decreased by $5 \%$ from the high stress group to moderate stress group (Tables 2 and 3). According to Ko (2010), factors such as life satisfaction and stress affect mental health and thus are mutually correlated. Moreover, stress that is generally experienced by the elderly has various factors such as individual, psychological, social and environmental factors, and the report by Lee and Kim (1999) that suicidal ideation increases when they face difficulty in coping with these situations represents the risks of the high stress group.

\section{Depression scale of participants}

As a result of analyzing the depression scale and ratio of participants before and after participating in the agrohealing program (Table 4), it was found that SGDS-K did not show a statistically significant difference before and after the program. Stress levels were very high in this study,

Table 2. Comparisons of stress levels before and after seven sessions of agro-healing activities in elderly participants

\begin{tabular}{|c|c|c|c|c|}
\hline & \multicolumn{2}{|c|}{$\mathrm{M} \pm \mathrm{SD}$} & \multirow{2}{*}{$z$} & \multirow{2}{*}{$p$} \\
\hline & Before & After & & \\
\hline Stress levels & $4.31 \pm 0.87$ & $4.17 \pm 0.92$ & -.855 & $.393^{\mathrm{NS}}$ \\
\hline
\end{tabular}

Note. 5-point Likert scale was used to measure stress levels.

${ }^{\mathrm{NS}}$ Non-significant by Wilcoxon paired singed-rank test $(\mathrm{N}=20)$.

Table 3. Changes in elderly participants' stress zone after seven sessions of agro-healing activities

\begin{tabular}{cccc}
\hline & \multicolumn{3}{c}{ Stress zone $^{\mathrm{z}}(\%)$} \\
\cline { 2 - 4 } & Low & Moderate & High \\
\hline Before & 0.0 & 5.0 & 95.0 \\
After & 0.0 & 10.0 & 90.0 \\
\hline
\end{tabular}

Note. 5-point Likert scale was used to measure stress levels.

${ }^{\mathrm{z}}$ High stress zone $=$ average rating 2.8 or higher out of 5 ; moderate stress zone $=$ average rating $1.8-2.6$ out of 5 ; low stress zone $=$ average rating 1.6 or lower out of 5 .

Table 4. Comparisons of depression scales before and after seven sessions of agro-healing activities in elderly participants

\begin{tabular}{|c|c|c|c|c|}
\hline & \multicolumn{2}{|c|}{$\mathrm{M} \pm \mathrm{SD}$} & \multirow[b]{2}{*}{2} & \multirow{2}{*}{$p$} \\
\hline & Before & After & & \\
\hline Depression & $4.40 \pm 2.60$ & $4.80 \pm 3.04$ & -.525 & $.600^{\mathrm{NS}}$ \\
\hline
\end{tabular}

Note. 2-point scale was used for 15 items, where $0=y e s ; 1=$ no.

${ }^{\mathrm{NS}}$ Non-significant by Wilcoxon paired singed-rank test $(\mathrm{N}=20)$. 
but depression levels were less than 5 points before and after the program, showing a normal state.

\section{Satisfaction of participants in the program and number of chronic diseases they have}

As a result of examining satisfaction with the agro-healing program, $50.0 \%$ were very satisfied and $25.0 \%$ were satisfied, showing a high satisfaction overall $75 \%$ (Table 5). The number of diseases that the participants currently have was examined through multiple response analysis, and the result showed that 19 out of 20 participants except one had chronic diseases, and five of them had at least three diseases at the same time. Most of them had hypertension $35.6 \%$, followed by hyperlipidemia $19.6 \%$, diabetes $17.8 \%$, arthritis $11.0 \%$, lumbago $6.7 \%$, osteoporosis $6.7 \%$, and heart disease 2.2\% (Table 6). Hypertension patients suffer from higher stress levels than others (Lee and Han, 2000), and are put under mental burdens such as stress, anxiety and depression due to chronic psychological conflicts. Thus, according to Park et al. (1992), hypertension patients face lower quality of life than those without blood pressure. Gerdin et al. (2005) reported that now is the time measures must be taken for the problem of the aged, which has become the most important social problem, in multiple aspects such as physical, mental and psychosocial due to aging. The fact that 5 out of 20 participants in the study have at least three chronic diseases, and that hypertension takes up the highest portion, represents the issue of the many diseases that the elderly participants have. Therefore, physical activities related to horticultural plants that use the five senses of humans such as plowing the soil, sowing seeds, watering plants and removing weeds (Matsuo and Miyajima, 1998) reduce depression or stress of the elderly with dementia or the elderly living in an institution (Kim, 2009; Kim, 2013), and reduce blood pressure and pulses (Jang et al., 2019), which support the usefulness of the agro-healing program in this study.

\section{Changes in cortisol and blood pressure of participants}

As a result of analyzing salivary cortisol, which is a stress hormone, to examine the changes before and after
Table 5. Program satisfaction of elderly participants

\begin{tabular}{ccccc}
\hline \multicolumn{5}{c}{ Program satisfaction(\%) } \\
\hline $\begin{array}{c}\text { Very } \\
\text { unsatisfied }\end{array}$ & Unsatisfied & Neutral & Satisfied & $\begin{array}{c}\text { Very } \\
\text { satisfied }\end{array}$ \\
\hline 10.0 & 0.0 & 15.0 & 25.0 & 50.0 \\
\hline
\end{tabular}

Note. 5-point Likert scale was used, where $1=$ very unsatisfied; $5=$ very satisfied.

Table 6. Types of chronic diseases that elderly participants have $(\mathrm{N}=20)$

\begin{tabular}{lcc}
\hline \multicolumn{1}{c}{ Variable } & Frequency & Percent (\%) \\
\hline Arthritis & 5 & 11.0 \\
Hypertension & 16 & 35.6 \\
Lumbago & 3 & 6.7 \\
Hyperlipidemia & 9 & 20.0 \\
Osteoporosis & 3 & 6.7 \\
Diabetes & 8 & 17.8 \\
Heart disease & 1 & 2.2 \\
\hline
\end{tabular}

participating in the agro-healing program, there was no statistical significance (Table 7). However, the result of analyzing blood pressure (Table 8) showed that systolic blood pressure decreased from $144.75 \mathrm{mmHg}$ (stage 1 hypertension) to $132.90 \mathrm{mmHg}$ (prehypertension stage) after participating in the program, showing statistical significance $(p<.001)$. The study by Jang et al. (2019) that participants in agro-healing activities showed a decrease in systolic blood pressure from the prehypertension stage to normal blood pressure after participation, and the studies by Ulrich (1981) and Kwak (2004) that plant cultivation and activities using natural objects in artificial spaces like modern apartments not only have environmental effects but also emotional effects such as psychological stability and stress relief, support the results of this study in which stress has decreased through agro-healing activities.

\section{Correlation among the demographic characteristics, psychological scale and number of diseases of participants}

As a result of examining the correlation among the demographic characteristics, psychological scale and number of diseases of participants (Table 9), there was a positive 
Table 7. Comparison of cortisol levels before and after seven sessions of agro-healing activities in elderly participants

\begin{tabular}{|c|c|c|c|c|}
\hline & \multicolumn{2}{|c|}{$\mathrm{M} \pm \mathrm{SD}$} & \multirow{2}{*}{$z$} & \multirow{2}{*}{$p$} \\
\hline & Before & After & & \\
\hline Saliva cortisol (ug/dL) & $0.108 \pm 0.05$ & $0.109 \pm 0.04$ & -0.178 & $.859^{\mathrm{NS}}$ \\
\hline
\end{tabular}

Note. $\mathrm{N}=12$.

${ }^{\mathrm{NS}}$ Non-significant by Wilcoxon paired singed-rank test.

Table 8. Comparisons of blood pressure before and after seven sessions of agro-healing activities in elderly participants

\begin{tabular}{|c|c|c|c|c|}
\hline & \multicolumn{2}{|c|}{$\mathrm{M} \pm \mathrm{SD}$} & \multirow{2}{*}{$z$} & \multirow{2}{*}{$p$} \\
\hline & Before & After & & \\
\hline Systolic blood pressure (mmHg) & $144.75 \pm 15.91$ & $132.90 \pm 13.88$ & -3.381 & $.001 * * *$ \\
\hline Diastolic blood pressure (mmHg) & $79.15 \pm 10.82$ & $76.65 \pm 8.43$ & -1.928 & .054 \\
\hline
\end{tabular}

Note. $\mathrm{N}=20$.

${ }^{\mathrm{Ns}}$ Non-significant, $* * * p<.001$ by Wilcoxon paired signed-rank test.

Table 9. The correlation between sociodemographic background, psychological scale and number of diseases of elderly participatants

\begin{tabular}{|c|c|c|c|c|c|c|c|c|c|c|c|}
\hline $\mathrm{V}^{\mathrm{z}}$ & A & $\mathrm{B}$ & $\mathrm{C}$ & $\mathrm{D}$ & $\mathrm{E}$ & $\mathrm{F}$ & $\mathrm{G}$ & $\mathrm{H}$ & I & $\mathrm{J}$ & $\mathrm{K}$ \\
\hline A & 1 & & & & & & & & & & \\
\hline B & .118 & 1 & & & & & & & & & \\
\hline $\mathrm{C}$ & -.449 & $-.501^{*}$ & 1 & & & & & & & & \\
\hline D & .154 & .424 & $-.528^{*}$ & 1 & & & & & & & \\
\hline E & -.278 & $-.611^{* *}$ & $.584^{* *}$ & -.173 & 1 & & & & & & \\
\hline $\mathrm{F}$ & .232 & -.068 & -.153 & .276 & .122 & 1 & & & & & \\
\hline G & .066 & -.123 & -.129 & -.046 & .044 & .434 & 1 & & & & \\
\hline $\mathrm{H}$ & .220 & -.242 & .105 & .091 & -.133 & -.248 & -.162 & 1 & & & \\
\hline I & $.455^{*}$ & .033 & .132 & -.197 & -.170 & .111 & .088 & .323 & 1 & & \\
\hline $\mathrm{J}$ & .017 & .031 & .043 & -.131 & -.115 & .096 & $-.489 *$ & -.223 & .226 & 1 & \\
\hline K & .067 .067 & .150 & -.189 & $.577 * *$ & .133 & $.462^{*}$ & .170 & .084 & .147 & -.006 & 1 \\
\hline
\end{tabular}

${ }^{\mathrm{z}} \mathrm{V}=$ variable; $\mathrm{A}=$ gender; $\mathrm{B}=$ age; $\mathrm{C}=$ education; $\mathrm{D}=$ average pharmacy visits per month; $\mathrm{E}=$ =monthly income; $\mathrm{F}=$ pre-depression; $\mathrm{G}=$ post-depression; $\mathrm{H}=$ pre-stress value; $\mathrm{I}=$ post-stress value; $\mathrm{J}=$ program satisfaction; $\mathrm{K}=$ disease counts.

${ }^{*} p<.05, \stackrel{* *}{*}<.01(\mathrm{~N}=20)$.

correlation with gender and posttest stress, and negative correlation with age, education level and average monthly income, showing statistical significance. Moreover, there was a negative correlation with education level and average monthly visit to the pharmacy, and positive correlation with average monthly income. There was a positive correlation with average monthly visit to the pharmacy, pretest depression and number of diseases, and negative correlation with posttest depression and satisfaction, showing statistical significance. This result showed that, although there is a huge gap in the male-female ratio among the participants, correlation by gender proved that male participants showed higher stress recovery than female participants after participating in the program (data not shown). Moreover, younger participants led to higher education level and average monthly income, and higher education level led to fewer average monthly visits to the pharmacy and higher average monthly income. Higher average monthly visit to the pharmacy and depression led to more diseases and lower program satisfaction. Therefore, older participants with higher depression and lower education level had lower average monthly income and a bigger number of diseases. Low so- 
cioeconomic level is related to prevalence of cardiovascular disorders (Kaplan and Keil, 1993; Pekkanen et al., 1995), and low education level is related to hypertension (Brown et al., 2004; Kim, 2002), saccharometabolic abnormality and overweight accompanied by metabolic disorder, thereby affecting prevalence of cardiovascular disorders (Brunner et al., 1997), which supports the results of this study that higher education level and average monthly income lead to fewer diseases. Moreover, the report by Yi (2015) that older age leads to more visits to medical institutions due to hypertension, diabetes and degenerative arthritis shows similar results as this study.

\section{Conclusion}

To examine the psychological and physiological changes of the elderly according to agro-healing activities, this study conducted an agro-healing program once a week in total 7 sessions, 90 minutes each, on 20 male and female elderly participants with the average age of 77.6 \pm 5.84 . The Korean version of the Brief Encounter Psychosocial Instrument (BEPSI-K) and the Korean version of the Short Form of Geriatric Depression Scale (SGDS-K) were used to measure the psychological state, and program satisfaction, salivary cortisol (Salivettes system) and blood pressure are also measured, before Session 1 and after Session 7. As a result of analyzing the pretest and posttest results, it was found that BEPSI-K and SGDS-K were not statistically significant after participating in the program, but BEPSI-K decreased by $5 \%$ in the high stress group. As a result of examining program satisfaction, $50.0 \%$ were very satisfied and $25.0 \%$ were satisfied, showing a high satisfaction overall at $75 \%$. As for the diseases that the participants currently have, most of them (35.6\%) had hypertension, followed by hyperlipidemia, diabetes, arthritis, lumbago, osteoporosis, and heart disease. Moreover, the result of analyzing salivary cortisol, which is a stress hormone, showed that there was no statistical significance. However, the analysis of blood pressure showed that systolic blood pressure decreased from $144.75 \mathrm{mmHg}$ (stage 1 hypertension) to $132.90 \mathrm{mmHg}$ (prehypertension stage) after the program, showing statistical significance $(p<.001)$.
This is very useful for the elderly that participated in this study with hypertension or diabetes, as supported by Jang et al. (2019) reporting that participants in agro-healing activities showed a decrease in systolic blood pressure from the prehypertension stage to normal blood pressure after participation. As a result of examining the correlation among general matters such as age, education level and average income of participants, psychological scale and number of diseases, program satisfaction showed a negative correlation with depression. This indicates that higher satisfaction with the agro-healing program led to lower depression. Although there is individual difference, elderly depression is the most common and typical mental disorder in senescence, and it is an emotional disturbance that appears due to weakening sensory functions, negative emotions and concerns about themselves, helplessness, sense of loss, and lack of meaning of life, mostly accompanied by depressive symptoms (Korean Neuro Psychiatric Association, 2005). Horticultural activities can be one of the most beneficial treatments for the elderly facing quicker degeneration of mental and physical functions, while also promoting rehabilitation for those with chronic diseases and preventing geriatric diseases (Relf, 1992). Moreover, Mcgurie (1997) reported that horticultural activities can give a sense of achievement and help recover emotional stability and sociality by stimulating sensory functions, recalling memories of the past and having interactions and conversations within other members of the group, which supports the importance of agro-healing activities. Furthermore, the results of this study prove that agro-healing activities are very useful in lowering stress or blood pressure of the elderly generation that more commonly suffers from hypertension. In addition, they are proved to have positive uses in reducing the problems of the modern society with severe issues of the aging population as well as many elders living alone.

\section{References}

Bae, J.M., E.K. Jeong, T.W. Yoo, B.Y. Huh, and C.H. Kim. 1992. A quick measurement of stress in outpatient clinic setting. J. Korean Acad. Fam. Med. 13(10):809-820. 
Brown, E.S., F.P. Varghese, and B.S. McEwen. 2004. Association of depression with medical illness: Does cortisol play a role? Biol. Psychiatry 55(1):1-9.

Brunner, E.J., M.G. Marmot, K. Nanchahal, M.J. Shipley, S.A. Stansfeld, M. Juneja, and K.G. Alberti. 1997. Social inequality in coronary risk: Central obesity and the metabolic syndrome. Evidence from the whitehall II study. Daibetologia 40(11):1341-1349.

Cho, M.J., J.N. Bae, G.H. Suh, B.J. Hahm, J.K. Kim, D.W. Lee, and M.H. Kang. 1999. Validation of geriatric depression scale, Korean version(GDS) in the assessment of DSM-III-R major depression. J. Korean Neuropsychiatr. Assoc. 38(1):48-63.

Choi, S.H., I.S. See, I.J. Song, O.J. Kwon, K.O. Park, H.J. Hong, K.K. Sung, and S.K. Lee. 2014. Method of saliva collection for salivary cortisol measurement. Korean J. Orient. Physiol. Pathol. 28(2):223-232. http s://doi.org/10.15188/kjopp.2014.04.28.2.223

Frank, S.H. and S.J. Zyzanski. 1988. Stress in the clinical setting: the brief encounter psychosocial instrument. J. Fam. Pract. 26(5):533-539.

Gerdin, E.W., S. Einarson, M. Jonsson, K. Aronsson, and I. Johansson. 2005. Impact of dry mouth conditions on oral health-related quality of life in older people. Gerodontology 22(4):219-226.

Hewson, M.L. 1994. Horticulture as therapy: a practical guide to using horticulture as a therapeutic tool. Enumclaw, WA: Idyll Arbor.

Jang, H.S., E.H. Yoo, S.J. Jeong, J.S. Kim, and D.Y. Ryu. 2019. Effects of an agro-healing activity program on the physiological condition of adults with chronic metabolic diseases. J. People Plants Environ. 22(4):355-364. https://doi.org/10.11628/ksppe.2019.22.4.355

Jang, J.H., S.H. Baik, A.J. Kim, S.H. Jung, O.S. Kim, and S.H. Kim. 2006. The effect of xerostomia on perceived oral health among elderly people wearing dentures. J. Korean Acad. Oral Health 30(4):438-446.

Jeong, S.J., S. Apostilska, M. Jankulovska, D. Angelova, S. Nares, M.S. Yoon, D.S. Lim, N. Angelov, and M.J. Jeong. 2006. Dental caries risk can be predicted by simply measuring the $\mathrm{pH}$ and buffering capacity of saliva. J. Dent. Hyg. Sci. 6(3):159-162.
Jung, C.H., J.S. Park, W.Y. Lee, and S.W. Kim. 2002. Effects of smoking, alcohol, exercise, level of education, and family history on the metabolic syndrome in Korean adults. Korean J. Med. 63(6):649-659.

Kaplan, G.A. and J.E. Keil. 1993. Socioeconomic factors and cardiovascular disease: A review of the literature. Circulation 88(4 Pt 1):1973-1998.

Kim, B.S. 2002. Prevalence of metabolic syndrome for Koreans-among the clients of comprehensive medical examination center in one university hospital. Korean J. Health Promot. Dis. Prev. 2(1):17-26.

Kim, E.H. 2005. The effects of Korean traditional music, natural sound meditation music and synchronicity meditation music on the relief of female office worker's stress. Master's thesis, Changwon National University, Changwon, Korea.

Kim, E.J. 1998. The effect of perceived efficacy improvement program on psychosocial well-being of the elderly. Master's thesis, Ewha Womans University, Seoul, Korea.

Kim, H.Y. 2013. Effects of community garden construction and horticultural activities on the life-satisfaction of rural residents. Doctoral dissertation, Chungnam National University, Taejon, Korea.

Kim, J.Y. 2009. Age and depression in Korean adults. Health Soc. Sci. 26:89-113. Retrieved from http://kahms.re.kr

Kim, K.N., J.Y. Park, T.S. Shin, K.J. Jun, E.Y. Choi, H.J. Kim, S.H. Lee, T.W. Yoo, and B.Y. Huh. 1998. Degree of stress and stress-related factors by the Korean version of the BEPSI. J. Korean Acad. Fam. Med. 19(7):559-570.

Kim. K.T., J.M. Kim, J.H. Kim, K.W. Song, S.H. Oh, Y.D. Yoon, H.S. Yoon, C.J. Lee, B.N. Cho, and E.G. Hong. 2008. Endocrinology (6th ed.). Seoul, Korea: Bioscience.

Ko, G.D. 2010. The effect of elderly's participation in health promotion programs on life satisfaction, self-esteem, stress, and mental health. Master's thesis, Sunchon National University, Sunchon, Korea.

Korean Neuro Psychiatric Association. 2005. Textbook of neuropsychiatry (2nd ed.). Seoul, Korea: Joongang Munhwa.

Kwak, S.O. 2004. A study on the environmental market- 
ing for interior scape within apartment. Doctoral dissertation, Sangmyung University, Cheonan, Korea.

Lazarus, R.S. 1993. From psychological stress to the emotions: A history of changing outlooks. Annu. Rev. Psychol. 44:1-22. https://doi.org/10.1146/annurev.ps.44.020193.000245

Lee, P.S. and K.S. Han. 2000. Symptoms of stress in essential hypertension. J. Korean Acad. Psychiatr. Ment. Health Nurs. 9(3):292-302.

Lee, S.H. 1999. Effect of horticultural therapy on the changes of depression and self esteem of demented old adults. Master's thesis, Konkuk University, Seoul, Korea.

Lee, Y.J. and T.H. Kim. 1999. A study on the buffering effect of social support on the stress of the elderly who lives alone. J. Korean Gerontol. Soc. 19(3):79-93.

Matsuo, E. and I. Miyajima. 1998. Up-to-date trend of horticultural therapy in Japan-an attempt to redefine horticulture in horticultural therapy and place horticultural therapy in relation to other therapies. J. Korean Soc. People Plants Environ. 1(1):22-33.

McGuire, D.L. 1997. Implementing horticultural therapy into a geriatric long-term care facility. Act. Adapt. Aging 22(1-2):61-80. https://doi.org/10.1300/J016v22n01_06

Oh, J.Y., D.B. Park, and H.J. Kim. 2019. The relationship between systemic disease and salivary secretion of the elderly and PH of saliva. Asia Pac. J. Multimed. Serv. Converg. Art Humanit. Sociol. 9(4):427-436. https://d oi.org/10.21742/AJMAHS.2019.04.41

Park, K.M., H.S. Kim, K.S. Kim, H.C. Shin, and E.S. Park. 1992. The comparison of quality of life between hypertension patients and normal control subjects. J. Korean Acad. Fam. Med. 13(3):240-245.

Pekkanen, J., J. Tuomilehto, A. Uutela, E. Vartiainen, and A. Nissinen. 1995. Social class, health behaviors, and mortality among men and women in eastern Finland. BMJ 311(7005):589-593. https://doi.org/10.1136/bmj.311.7005.589

Petersen, P.E. and T. Yamamoto. 2005. Improving the oral health of older people: the approach of the WHO global oral health programme. Community Dent. Oral
Epidemiol. 33(2):81-92.

Posener, J.A., C. DeBattista, G.H. Williams, H.C. Kraemer, B.M. Kalehzan, and A.F. Schatzberg. 2000. 24-hour monitoring of cortisol and corticotropin secretion in psychotic and nonpsychotic major depression. Arch. Gen. Psychiatry 57(8):755-760.

Relf, P.D. 1992. The role of horticultue in human well-being and social development: A national symposium, 19-21 April 1990, Arlington, Virginia. Portland, USA: Timber Press.

Saliva. n.d. In Naver Encyclopedia of Knowledge. Retrieved September 5, 2019 from https://terms.naver.com

Schwartz, E.B., D.A. Granger, E.J. Susman, M.R. Gunnar, and B. Laird. 1998. Assessing salivary cortisol in studies of child development. Child Dev. 69(6):1503-1513.

Shin, H.C., C.H. Kim, Y.W. Park, B.L. Cho, S.W. Song, Y.H. Yun, and S.W. Ou. 2000. Validity of Zung's self-rating depression scale: Detection of depression in primary care. J. Korean Acad. Fam. Med. 21(10):1317-1329.

Ulrich, R.S. 1981. Natural versus urban scenes: Some psychophysiological effects. Environ. Behav. 13(5):523-556. https://doi.org/10.1177/0013916581135001

Yang, S.B., H.S. Moon, D.H. Han, H.Y. Lee, and M.K. Chung. 2008. Oral health status and treatment need of institutionalized elderly patients. J. Korean Acad. Prosthodont. 46(5):455-469.

Yesavage, J.A., T.L. Brink, T.L. Rose, O. Lum, V. Huang, M. Adey, and V.O. Leirer. 1983. Development and validation of a geriatric depression screening scale a preliminary report. J. Psychiat. Res. 17(1)37-49.

Yi, J.U. 2015. Medical care utilization in adults and in chronic disease patients: focusing on the influence of private health insurance. Master's thesis, Seoul National University, Seoul, Korea.

Yim, J.H., J.M. Bae, S.S. Choi, S.W. Kim, H.S. Hwang, and B.Y. Huh. 1996. The validity of modified Korean-translated BEPSI(Brief Encounter Psychosocial Instrument) as instrument of stress measurement in outpatient clinic. J. Korean Acad. Fam. Med. 17(1):42-53. 